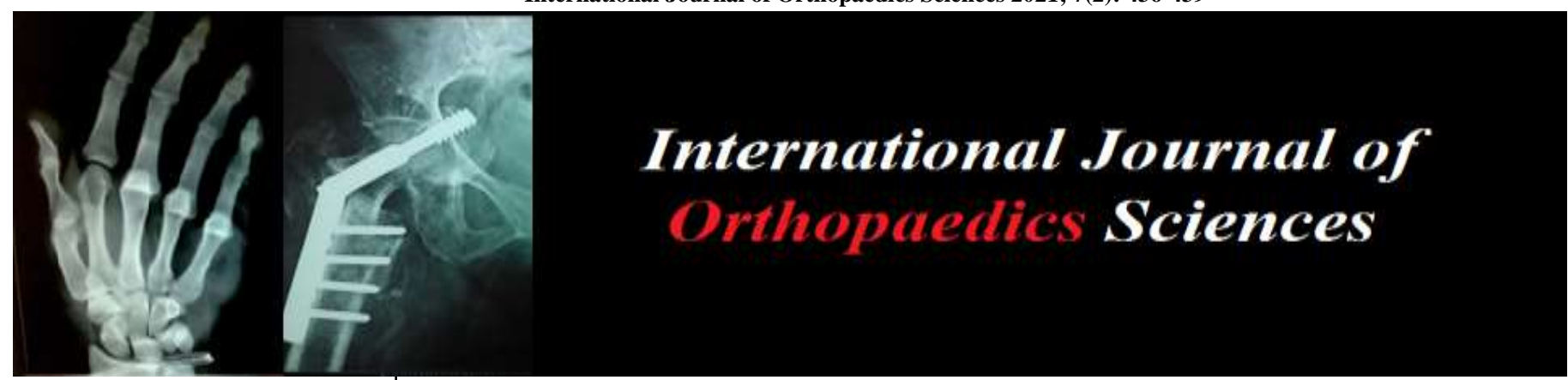

E-ISSN: 2395-1958

P-ISSN: 2706-6630

IJOS 2021; 7(2): 436-439

(C) 2021 IJOS

www.orthopaper.com

Received: 13-02-2021

Accepted: 20-03-2021

Dr. Santosh Veershetty Patil Assistant Professor, Department of Orthopaedics, Maheshwara Medical College and Hospital, Isnapur, Telangana, India

\section{Efficacy of the PHILOS plate in the management and functional outcome of proximal humerus fractures: A prospective study}

\section{Dr. Santosh Veershetty Patil}

DOI: https://doi.org/10.22271/ortho.2021.v7.i2f.2660

Abstract

Proximal humerus fractures management is a challenging task for orthopaedic surgeons due to the high incidence of postoperative complication. PHILOS plate is the recent advancement in locking plate fixation for proximal humerus fractures which provides angular stability and compression that lead to a speedy recovery. The present study was designed to assess the efficacy of the PHILOS plate in the management of displaced fractures to the proximal humerus. A total of 40 cases with displaced proximal humerus fractures admitted in the Department of Orthopedics were recruited. Patients were undergoing Open reduction internal fixation with PHILOS locking plating for the sustained fracture under general anaesthesia. Postoperative follow up appointments were conducted at the end of 2 weeks, 6 weeks, 3 months, 6 months and 12 months. Road traffic accidents were the commonest mode of injury in $72.5 \%$ of cases, followed by falling injuries from height (20\%) and injuries by falling and slipping (7.5\%). The mean constant- murley score was 66.25 . The functional outcome was excellent in $20 \%$ cases, good in $30 \%$ cases, fair in $35 \%$ cases and poor in $15 \%$ cases. No severe postoperative complications observed. The proximal humerus locking plate is a good treatment option for 2, 3 and 4 part of NEER's fractures with good functional outcome, good stable fixation with minimal postoperative complications.

Keywords: Proximal humeral internal locking system (PHILOS), proximal humerus fractures, functional outcome, constant-murley score

\section{Introduction}

Proximal humerus fractures is second common fractures of the upper extremity accounts for about $5 \%$ of all injuries to the appendicular skeleton, $4 \%$ of total fractures and $26 \%$ of humerus fractures ${ }^{[1]}$. Incidence of proximal humerus fractures is more common in women and old age people with osteoporosis. The complex fractures and dislocations are often seen in active, middle aged cases ${ }^{[2,3]}$. The surgical management of proximal humerus fractures is a challenging task for orthopaedician due to the high incidence of postoperative complications and a wide variety of fracture patterns. To obtain a satisfactory functional outcome, accurate anatomical reduction gains and early fracture fixation are more important than the adapted surgical procedure and type and design of implant used ${ }^{[4]}$.

There are several techniques available for fixation of proximal humerus fractures such as Kwire, bone sutures, tension band wires, cerclage wires, prosthetic replacement and intramedullary devices ${ }^{[5]}$. The proximal humeral internal locking system (PHILOS) plate is a recent generation locking compression plates in which screws were placed in converging and diverging directions to provide stable fixation and allows early postoperative mobilization ${ }^{[6,7]}$. However, with the limited availability of prospective studies upon the management of proximal humerus fractures treated with PHILOS plate. The present study was designed to assess the efficacy of the PHILOS plate in the management and functional outcome of displaced proximal humerus fractures.

\section{Materials and Methods}

The present prospective study was conducted in the Department of Orthopedics, Maheshwara Medical College and Hospital, Isnapur, Telangana from March 2019 to March 2021.
Corresponding Author:
Dr. Santosh Veershetty Patil Assistant Professor, Department of Orthopaedics, Maheshwara Medical College and Hospital, Isnapur, Telangana, India 
A total of 40 cases with displaced proximal humerus fractures admitted in the Department of Orthopedics were recruited. Cases with a mature skeletal framework, fractures to the proximal part of the humerus according to NEER 2 part, 3 part and 4 part fractures and cases willing to participate been included. Cases with an immature skeletal framework, open fractures, pathological fractures and cases not willing to participate in the study were excluded. Informed consent was obtained from all the study participants and the study protocol was approved by the institutional ethics committee.

All the subjects were evaluated clinically and treated accordingly. Preoperatively, all the subjects were undergone with X-ray to analyze the type of fracture with the help of NEER's classification. Few cases were undergone with CT scan, to assess the extent of articular fracture. All the study participants were operated with PHILOS plate under the guidance of $\mathrm{C}$-arm. Cases were operated in the supine position on a radiolucent table under general anaesthesia through anterior deltopectoral approach.

Postoperatively, the arm was immobilized in arm pouch with a cuff and a collar sling. Drain exit was done on $2^{\text {nd }}$ postoperative day. For a stable fixation, pendulum exercises and other passive ROM as tolerated were advised to the patient. Postoperative follow up appointments were conducted at the end of 2 weeks, 6 weeks, 3 months, 6 months and 12 months. During follow up, cases were evaluated clinically for status of wound, severity of pain, tenderness, swelling, range of motion and status of infection and radiological for healing of fracture, reduction and position of plate. The SPSS version 23 software was used to carry out statistical analysis relevant to the study. Descriptive statistics were used to represent demographic and clinical characteristics in the form of frequency and percentages.

\section{Results}

Table 1: Demographic details of study participants

\begin{tabular}{|c|c|c|}
\hline Demographic parameter & Frequency & Percentage \\
\hline \multicolumn{3}{|c|}{ Age (In years) } \\
\hline $28-40$ & 12 & $30 \%$ \\
\hline $51-50$ & 09 & $22.5 \%$ \\
\hline $61-70$ & 10 & $25 \%$ \\
\hline Above 70 Gender \\
\hline \multicolumn{3}{|c|}{ Laterality } \\
\hline Male & 03 & $7.5 \%$ \\
\hline Female Mode of injury \\
\hline \multicolumn{3}{|c|}{23} \\
\hline Unilateral right & 22 & $57.5 \%$ \\
\hline Unilateral left & 18 & $42.5 \%$ \\
\hline Bilateral & 08 & $20 \%$ \\
\hline \multicolumn{2}{|c|}{ - } & - \\
\hline Falling injuries from height & 03 & $7.5 \%$ \\
\hline Falling and slipping & 29 & $72.5 \%$ \\
\hline Road traffic accidents & $06 \%$ \\
\hline Types of fracture (NEER's classification) \\
\hline 2 part fracture & 05 & $12.5 \%$ \\
\hline 3 part fracture & 27 & $67.5 \%$ \\
\hline 4 part fracture & 08 & $20 \%$ \\
\hline
\end{tabular}

Table 2: Average constant score in related to age and NEER's classification.

\begin{tabular}{|c|c|c|c|c|}
\hline & Average constant score & Range & Frequency & Percentage \\
\hline Mean constant score & \multicolumn{4}{|c|}{ A6.22 (range 43-84) } \\
\hline \multicolumn{5}{|c|}{ Age (In years) } \\
\hline $28-40$ & 71.3 & - & 12 & $30 \%$ \\
\hline $41-60$ & 63.9 & - & 19 & $47.5 \%$ \\
\hline Above 60 & 61.06 & - & 09 & $22.5 \%$ \\
\hline \multicolumn{5}{|c|}{ NEER's classification } \\
\hline 2 part fracture & 74.8 & $69-80$ & 05 & $12.5 \%$ \\
\hline 3 part fracture & 65.68 & $45-84$ & 27 & $67.5 \%$ \\
\hline 4 part fracture & 61.24 & $43-76$ & 08 & $20 \%$ \\
\hline
\end{tabular}

Table 3: Functional outcome grading in the study participants

\begin{tabular}{|c|c|c|}
\hline Outcome & Frequency & Percentage \\
\hline Excellent & 08 & $20 \%$ \\
\hline Good & 12 & $30 \%$ \\
\hline Moderate & 14 & $35 \%$ \\
\hline Poor & 06 & $15 \%$ \\
\hline
\end{tabular}

Table 4: Postoperative complication of PHILOS plate.

\begin{tabular}{|c|c|c|}
\hline Complication & Frequency & Percentage \\
\hline Failure of fixation & 01 & $2.5 \%$ \\
\hline Malunion/non union & - & - \\
\hline Infection & 02 & $5 \%$ \\
\hline stiffness & 05 & $12.5 \%$ \\
\hline Perforation of screw & 02 & $5 \%$ \\
\hline Implant loosening & 01 & $2.5 \%$ \\
\hline osteonecrosis & 03 & $7.5 \%$ \\
\hline
\end{tabular}




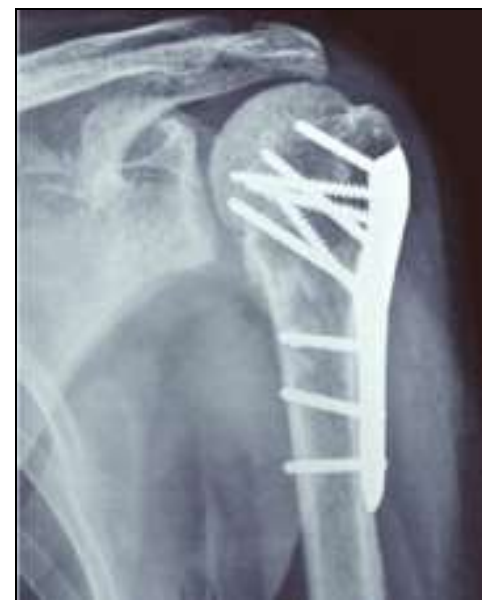

A. Preoperative

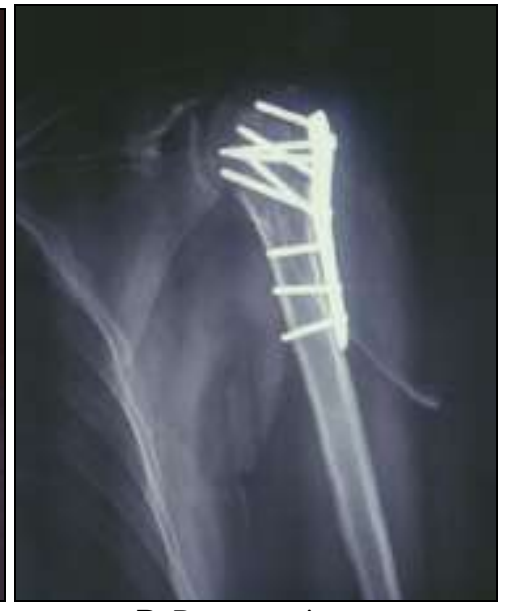

B. Postoperative

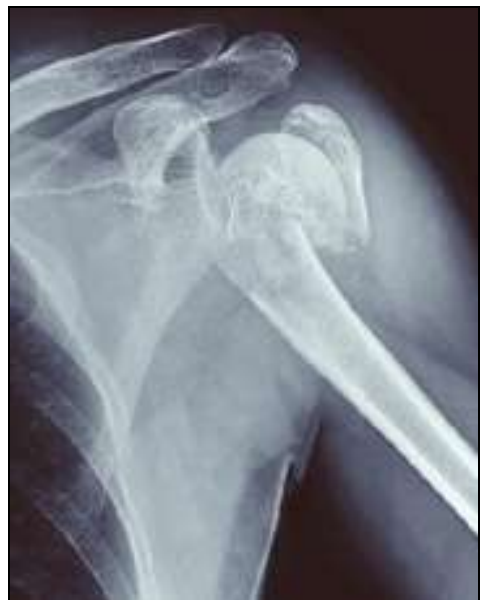

C. 6 months follow up

Fig 1: Radiographs of preoperative, postoperative and end of $6^{\text {th }}$ month follow-up of 42 years old male with proximal humerus fracture treated with PHILOS plate. (A. Preoperative, B. Post-operative \& C. $6^{\text {th }}$ month follow up)

\section{Discussion}

Proximal humerus fractures management is a challenging task for orthopaedician due to the high incidence of postoperative complication. PHILOS plate has been a widely accepted treatment modality for proximal humerus fractures. The present study was designed to assess the efficacy of PHILOS plate in the management of displaced fractures to proximal humerus. A total of 40 cases with displaced proximal humerus fractures admitted in the Department of Orthopedics were recruited. Majority cases in between 41-60 years $(47.5 \%)$, followed by $28-40$ years $(30 \%)$ and above 60 years $(22.5 \%)$. Male $(57.5 \%)$ participants were more than female cases $(42.5 \%)$. In this study, $55 \%$ of cases had fractures on the right humerus, $45 \%$ cases had fractures on the left humerus and none of the cases had bilateral humerus fractures. In this study, road traffic accidents were the commonest mode of injury in $72.5 \%$ cases, followed by falling injuries from height $(20 \%)$ and injuries by falling and slipping $(7.5 \%)$.

According to NEER's classification of fractures, $12.5 \%$ cases had 2 part fractures, $67.5 \%$ cases had 3 part fractures and $20 \%$ cases had 4 part fractures. In this study, the mean constant score was 66.25 and the range was 43-84. A study by Uidesh Yadav et al. to assess the functional outcome on 34 cases with 3 and 4 part proximal humerus fractures treated with PHILOS plate noticed that all the fractures united clinically and radiologically with a mean constant score at final follow up was $85.29^{[8]}$. A study by Vivek Bansal et al. included 25 cases with acute proximal humerus fractures to assess the functional outcome in these cases managed with PHILOS plate noticed a mean constant score after 6 months follow up was 57.4 and the constant score was poor in cases with 4 part fractures ${ }^{[9]}$. A study by Goutam Kumar Satpathy and Dillip Kumar Chand recruited 31 cases with proximal humerus fractures managed with PHILOS plate noticed a mean constant murley score at the final follow up was 81 (range 57100) ${ }^{[10]}$. A study by Jagiasi JD et al. noticed average constant score was 61.8. The mean constant score for above 45 years of age was 50.53 and for below 45 years of age was $72.91^{[13]}$. A study by P Kosala Raman et al. noticed average constant score after 18 months of follow up for all fractures was 67.28 [15]

In the present study, $20 \%$ of cases had excellent functional outcome, $30 \%$ cases had good functional outcome, $35 \%$ of cases had fair functional outcome and $15 \%$ cases had poor functional outcome (Table 3). A study by Vivek Bansal et al. found excellent outcome in $16 \%$ cases, good outcome in $44 \%$ cases, fair in $16 \%$ cases and poor outcome in $24 \%$ cases [9]. The functional outcome was excellent in 15 cases, good in 7 cases, fair in 5 cases and poor in 4 cases ${ }^{[10]}$. A study by Shivaprasad S et al. on 30 cases with proximal humerus fractures manages with PHILOS plate noticed excellent and satisfactory constant murley score in $90 \%$ cases and unsatisfactory outcome in $10 \%$ cases ${ }^{[11]}$. A study by Ali M and Wajid MA found the mean constant score for the operated shoulder was 62.3 as compared to 90.3 for the contralateral shoulder ${ }^{[12]}$. The functional outcome of cases as per grading of constant score was excellent in $40 \%$ cases, very good in $6.66 \%$, good in $30 \%$ cases, fair in $20 \%$ cases and poor in $3.33 \%$ cases ${ }^{[13]}$. A study by Srikanth $\mathrm{S}$ et al. noticed excellent results in $66.67 \%$ cases, good results in $16.67 \%$ cases and poor results in $10 \%$ cases ${ }^{[16]}$. A study by Rao NVN and Supradeeptha noticed an excellent constant murley score in 1 case, good score in 11 cases, moderate score in 11 cases and poor score in 2 cases ${ }^{[17]}$. A study by Kumar $\mathrm{V}$ et al. found excellent results in 7 cases, good results in 16 cases, satisfactory results in 5 cases and poor results in 2 cases ${ }^{[18]}$. A study by Vijay Sharma et al. found an excellent constant score in $50 \%$ cases, good outcome in $20 \%$ cases, moderate outcome in $20 \%$ cases and poor functional outcome in $10 \%$ cases ${ }^{[19]}$. A study by Dhruv Pandya and Krunal Soni noticed excellent and satisfactory functional outcome in $78 \%$ of cases and poor functional outcome in $22 \%$ of cases ${ }^{[20]}$.

A study by Uidesh Yadav et al. concluded that proximal humerus fractures treated with PHILOS plate give better functional and radiological outcome as compared to other fixation modalities like non-locking plates, intramedullary nails, $\mathrm{K}$ - wire fixation and tension band wiring ${ }^{[8]}$. A study by Vivek Bansal et al. concluded that management of proximal humerus fractures with PHILOS plate is associated with satisfactory functional outcomes in 2 and 3 part fractures ${ }^{[9]}$. A study by Goutam Kumar Satpathy and Dillip Kumar Chand concluded that PHILOS plating is a safe and effective treatment modality for proximal humerus fractures ${ }^{[10]}$. PHILOS plate is an effective modality in the management of proximal humerus fractures due to its angular stability ${ }^{[11]}$. Open reduction and internal fixation with PHILOS plate got better functional outcome with fewer implant related complications [12]. Management of proximal humerus fractures with PHILOS plate is a feasible modality and provides good stable fixation with the better functional outcome ${ }^{[13]}$. A study by Akram Muhammad Aliuddin et al. concluded that proximal humerus fractures treated with 
PHILOS plate have better functional outcome ${ }^{[14]}$. PHILOS is a reliable procedure with good functional outcome in the treatment of proximal humerus fractures ${ }^{[15]}$. PHILOS locking plates is a better treatment modality for proximal humerus fractures especially in cases of poor bone quality [16, 17]. PHILOS plate fixation is an effective treatment modality for proximal humerus fractures particularly in osteoporotic bones [18]. PHILOS plate provides good stable fixation with satisfactory functional outcome in the treatment of proximal humerus fractures ${ }^{[19]}$. PHILOS plate fixation is a promising modality in the management of proximal humerus fractures. It provides rigid fixation, enhances axial and angular stability and allows early mobilization of the shoulder ${ }^{[20,21]}$.

\section{Conclusion}

The proximal humerus fractures treated with PHILOS plate had excellent functional outcome in $20 \%$ cases, good in $30 \%$ cases, fair in $35 \%$ cases and poor in $15 \%$ cases by applying constant murley score. The proximal humerus locking plate is a good treatment option for 2, 3 and 4 part of NEER's fractures with good functional outcome, good stable fixation with minimal postoperative complications.

\section{References}

1. Court-Brown CM, Garg A, McQueen MM. The epidemiology of proximal humeral fractures. Acta Orthop Scand 2001;72(4):365-371.

2. Sumrein BO, Huttunen TT, Launonen AP, Berg HE, Felländer-Tsai L, Mattila VM. Proximal humeral fractures in Sweden-a registry-based study. Osteoporos Int 2017;28(3):901-907.

3. Holloway KL, Bucki-Smith G, Morse AG, BrennanOlsen SL, Kotowicz MA, Moloney DJ et al. Humeral Fractures in South-Eastern Australia: Epidemiology and Risk Factors. Calcif Tissue Int 2015;97(5):453-465.

4. Jose TM, Ajith Vincent T, Anil George Paul. Evaluation of the Outcome of Proximal Humerus Fracture Managed By Internal Locking Plate- A Prospective Study. IOSR Journal of Dental and Medical Sciences 2017;16(5):3643.

5. Chudik SC, Weinhold P, Dahners LE. Fixed-angle plate fixation in simulated fractures of proximal humerus: a biomechanical study of a new device. J Shoulder Elbow Surg 2003;12(6):578-88.

6. Yang H, Li Z, Zhou F, Wang D, Zhong B. A prospective clinical study of proximal humerus fractures treated with a locking proximalhumerus plate. J Orthop Trauma 2011;25:11-7.

7. Aggarwal S, Bali K, Dhillon MS, Kumar V, Mootha AK. Displaced proximal humeral fractures: an Indian experience with lockingplates. J Orthop Surg Res 2010;5:60.

8. Uidesh Yadav, Bharth $\mathrm{N}$, Vaithilingam Ramaiyah Vignesh, Akhil Chakrawarty. A comparative study of functional outcome following philos plating versus percutaneous pinning in proximal humerus fractures. Med Pulse International Journal of Orthopedics. November 2020;16(2):18-26.

9. Vivek Bansal, Sohal HS, Bhoparai RS. Philos Plate in Proximal Humerus Fracture-Its Functional Outcome and Complications. International journal of Orthopaedics 2015;2(3):1-8.

10. Goutam Kumar Satpathy, Dillip Kumar Chand. Functional outcome of proximal humerus fracture treated with philos plate. International Journal of Orthopaedics
Sciences 2017;3(2):169-172.

11. Shivaprasad S. Functional outcome of proximal humerus fracture with philos Plating. International Journal of Scientific Research 2020;9(2):36-39.

12. Ali M, Wajid MA. Early results of three and four part proximal humerus fractures treated with PHILOS (Proximal Humerus Interlocking System) plate. MOJ Orthop Rheumatol 2014;1(3):58-61. DOI: 10.15406/mojor.2014.01.00016

13. Jagiasi JD, Patel MR, Daliya SG, Bochare A, Vora M. Assessment of functional outcome of surgical management of proximal humerus fracture treated with PHILOS plate. Int J Res Orthop 2018;4:736-40.

14. Akram Muhammad Aliuddin, Zaki Idrees, Mehroze Zamir, Muhammad Kazim, Rahim Najjad, Syed Amir Ali Shah. Functional outcome of proximal humeral fractures treated with PHILOS plate in adults. J Ayub Med Coll Abbottabad 2016;28(2):337-340.

15. Kosala Raman P, Balamurugan $P$, Marimuthu $S$, Ragavanandam R. Functional outcome of proximal humerus fracture with PHILOS plating. International Journal of Orthopaedics Traumatology \& Surgical Sciences 2016;2(2):319-323.

16. Srikanth S, Reddy AVK, Omkarnath G. A study of proximal humerus fractures treated by PHILOS plating in a tertiary care hospital. Int J Res Orthop 2019;5:838-42.

17. Rao NVN, Supradeeptha C. Study on functional outcome of the proximal humeral internal locking system (PHILOS) for displaced proximal humeral fractures in adults. Surgical Update: Int $\mathbf{J}$ surg Orthopedics 2019;5(5):355-364.

18. Kumar V, Ahmed Khan A, Shah Ruchit et al. Assessment of functional outcome of PHILOS plate in proximal humerus fracture. J. Evid. Based Med. Healthc 2020;7(26):1218-1222.

19. Vijay Sharma, Balvinder Singh, Shailendra Khare. Management of Proximal Humeral Fractures with Proximal Humerus Locking Plate-A Prospective Study: Journal of Orthopaedics, Trauma and Rehabilitation. 2014;18(2):89-93.

20. Dhruv Pandya, Krunal Soni. "Analysis of Functional Outcome in Proximal Humerus Plating (PHILOS) in Displaced Proximal Humerus Fracture". Acta Scientific Orthopaedics 2020;3(11):37-49.

21. Lavesh Agrawal, Susheel Soni. To evaluate functional outcome of proximal humerus interlocking osteosynthesis (PHILOS) plating by constant \& murley scoring system for treatment of displaced proximal humerus fractures. National Journal of Clinical Orthopaedics 2019;3(1):125127. 